\title{
Anesthetic keratopathy presenting as bilateral Mooren-like ulcers
}

This article was published in the following Dove Press journal:

Clinical Ophthalmology

25 October 2012

Number of times this article has been viewed

\author{
Hamid Khakshoor \\ Majid Moshirfar ${ }^{2}$ \\ Rachel G Simpson ${ }^{3}$ \\ Hamid Gharaee' \\ Amir H Vejdani' \\ Steven M Christiansen ${ }^{2}$ \\ Jason $\mathrm{N}$ Edmonds ${ }^{2}$ \\ Nicholas L Behunin ${ }^{2}$ \\ 'Mashhad University of Medical \\ Sciences, Department of \\ Ophthalmology, Mashad, Iran; \\ ${ }^{2} J o h n$ A Moran Eye Center, University \\ of Utah, Salt Lake City, UT, ${ }^{3}$ The \\ University of Arizona College \\ of Medicine, Phoenix, AZ, USA
}

Correspondence: Majid Moshirfar 65 Mario Capechi Drive,

Salt Lake City, UT 84I32, USA

$\mathrm{Tel}+\mid$ 80I 58I 2352

Fax + 80I 58I3357

Email majid.moshirfar@hsc.utah.edu

\begin{abstract}
This observational case report describes the development of bilateral Mooren-like ulcers in a patient with anesthetic keratopathy. A 42-year-old man with a recent history of minor eye trauma and pain self-treated with tetracaine eye drops presented with complaints of acutely worsening vision and severe pain bilaterally. His visual acuity at presentation was limited to hand motion. Slit-lamp examination revealed bilateral epithelial defects at the center of the cornea, and an area of stromal infiltration and thinning with an undermining leading edge resembling a Mooren's ulcer in both eyes. Corneal haze and hypopyon were visible. Anesthetic use was halted immediately and the patient was started on prednisolone and mycophenolate mofetil $\left(\right.$ Cellcept $\left.^{\circledR}\right)$, after which visual acuity gradually improved and pain decreased. Despite improvement of symptoms, residual epithelial defects remained, and the patient was ultimately treated with keratoplasty for recovery of vision. We suggest that anesthetic keratopathy should be included in the differential diagnosis for any patient presenting with ring-shaped stromal infiltrates or nonhealing epithelial defects.
\end{abstract}

Keywords: anesthetic abuse, corneal damage, corneal ulceration

\section{Introduction}

The link between excessive or extended abuse of topical anesthetic drops and the development of a constellation of corneal abnormalities, grossly termed anesthetic keratopathy, is well established in the literature. The most common manifestations of this condition include acute pain and loss of vision, central corneal epithelial defects, ring keratitis, degenerative keratopathy with epithelial shedding, and stromal infiltration. ${ }^{1-5}$ In many cases, the symptoms of anesthetic keratopathy are mistaken for another disease, most frequently bacterial keratitis, either because the patient does not disclose a history of anesthetic use or because the physician is unaware of the link between topical anesthetic use and severe keratitis. ${ }^{2-4}$ Improper management of the acute phase of the disease and failure to stop the use of the offending eye drops may result in permanent vision loss. Therefore, it is critical to identify the underlying etiology quickly and correctly in cases of anesthetic keratopathy, because doing so may improve patient outcomes. ${ }^{1-5}$ In this study, we report an atypical case of anesthetic keratitis presenting as bilateral corneal ulcers strikingly similar to a Mooren's ulcer.

\section{Case report}

A 42-year-old man presented to Katam Al-Anbia Eye Hospital in Mashhad, Iran, with complaints of severe pain and acute vision loss bilaterally. His recent medical history was significant for a welding accident 2 months previously, at which time he sustained 
minor bilateral eye injuries. He reported having access to four $15 \mathrm{cc}$ bottles of topical anesthetic eye drops (preserved tetracaine), which he used frequently for pain following this injury. His current symptoms began one week prior to presentation. He initially sought treatment from his primary care physician, who prescribed a patch and topical antibiotics, which had no effect on symptoms. His physician then treated him for suspected bacterial keratitis with fortified cefazolin and amikacin, but symptoms worsened. It was at this time he was referred to Katam Al-Anbia for further evaluation.

On examination, uncorrected visual acuity was reduced to hand motion bilaterally. Slit-lamp examination revealed edematous eyelids, and a $5 \times 7 \mathrm{~mm}$ epithelial defect was identified in the center of the cornea bilaterally, with underlying dense, ring-shaped infiltrates involving both the superficial and deep stromal layers. The stroma was thinned for 360 degrees peripherally around the affected area, and an ulcer with an undermining leading edge resembling a Mooren's ulcer was clearly visible. No keratic precipitate was detectable. The anterior chamber had $1 \mathrm{~mm}$ of hypopyon. The lens, vitreous, and retina could not be evaluated because of hazy media (see Figure 1).

Topical tetracaine was promptly discontinued. Multiple corneal scrapings were obtained for a full microbiology workup. Culture and staining of all samples was negative for both bacterial and fungal infections, and there was no evidence of acanthamoeba on smear. The patient was prescribed preservative-free artificial tears (Artelac ${ }^{\circledR}$, Bausch and Lomb Company, Rochester, NY) hourly, oral steroid (prednisone $1 \mathrm{mg} / \mathrm{kg}$ ) was initiated, and the patient was scheduled for daily outpatient follow-up appointments. On day 5 of this treatment, the patient's condition had stabilized and the hypopyon resolved, but his uncorrected visual acuity

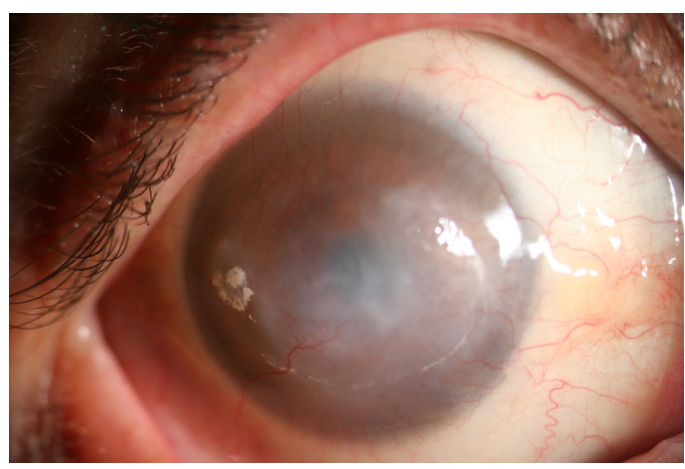

Figure I Corneal Haze in a Patient with Anesthetic Keratopathy.

Notes: Figure demontrates a central persistent epithelial defect with underlying stromal haze in a ring like distribution in a patient with a history of topical anesthetic abuse. The prominent corneal neovascularization approaching the visual axis. Peripheral thinning at the limbus is present for nearly 360 degrees. remained limited to hand motion, and the bilateral epithelial defects and stromal ring infiltration persisted. Mycophenolate mofetil $\left(\right.$ Cellcept $\left.^{\circledR}\right)$ was started at $500 \mathrm{mg}$ twice daily, and the patient was seen in clinic weekly for 4 weeks, and then every 2 weeks for 8 additional weeks, during which time he showed gradual improvement. He continued Cellcept and oral prednisone for 3 months. At the 3-month follow-up visit, pain was decreased and inflammation, while present, appeared well controlled. Uncorrected visual acuity had improved to counting fingers at $30 \mathrm{~cm}$, and ulcer progression had abated. A persistent epithelial defect remained in the central cornea (see Figure 2). At the time of writing, the patient is scheduled for keratoplasty for recovery of vision.

\section{Discussion}

Mooren's ulcer is a chronic, painful, and devastating peripheral ulcerative keratitis. The characteristic lesion begins in the periphery of the cornea and spreads circumferentially and then centripetally, with a leading undermining edge of de-epithelialized tissue that is initially confined to the periphery of the cornea. In more advanced cases, it can progress to involve the whole cornea. The condition has two distinct manifestations. Primary Mooren's ulcer is typically unilateral, occurs in an older patient population, is slowly progressive, and affects men and women with equal incidence. The secondary form of the disease is usually bilateral, rapidly progressive, and is more common in young men in developing countries. Development of secondary Mooren's ulcer is linked to previous incidence of ocular trauma or parasitic infection. The underlying etiology is unknown, although recent evidence strongly suggests an autoimmune component. Recent injury or infection is believed to alter the expression of corneal antigens. Cross-reactivity between the

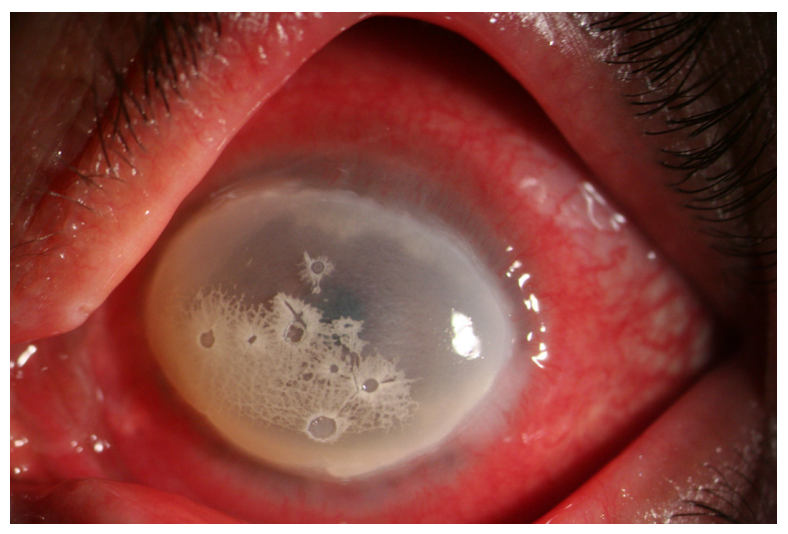

Figure 2 Corneal Ulceration in Anesthetic Keratopathy Resembling Mooren's Ulcer. Note: Figure demonstrates 360 degrees of corneal thinning at the limbus with a noticeable undermined edge, diffuse corneal haze is also observed. 
immune system and newly expressed corneal autoantigens then occurs. This theory of autoimmunity may explain the temporal link between previous infection or trauma and development of the ulcers. ${ }^{6}$

In this case, we hypothesize that use of topical anesthetic may have altered normal corneal antigens, leading to an autoimmune response. Increased immune activity and inflammatory cells further damage the cornea, in the process liberating more altered corneal antigens and perpetuating a cycle of destruction. The autoantibodies and inflammatory mediators attack the cornea, liberating more altered corneal antigens and perpetuating a cycle of destruction. As this cycle progresses, the patient experiences severe pain and in response increases use of the inciting agent, further perpetuating the cycle.

This case is the first report in the literature of anesthetic abuse presenting with Mooren-like ulcers. Previously described anesthetic keratopathy includes reports of superficial punctate keratopathy, persistent epithelial defects, Wessely immune ring-like or disciform stromal infiltration corneal edema, folding of Descemet's membrane, neurotrophic ulcer, and corneal perforation. ${ }^{1,7-10}$ When anesthetic keratitis is suspected, the first and most important aspect of treatment is to discontinue use of the inciting agent. ${ }^{1}$ Prompt diagnosis is critical, because patients often continue to use topical anesthetics for pain management until the diagnosis is reached and they are forced to quit. Our patient experienced significant delay before the appropriate treatment was initiated, due to failure to recognize the underlying etiology of his symptoms. Throughout that time he continued frequent use of tetracaine drops, which likely exacerbated his condition. In some cases, a patient may be reluctant to reveal use or abuse of anesthetic drops. A thorough ocular history and high level of suspicion are often needed to make the correct diagnosis in enough time to prevent permanent vision loss. ${ }^{11-13}$

Risk factors for developing anesthetic keratopathy include inconsistent use or overuse of prescribed anesthetic drops, inadequate patient counseling on proper use of these drops, poor patient monitoring and follow-up, as well as availability of over-the-counter anesthetic drops. ${ }^{1}$ Cases of anesthetic keratopathy occur more commonly in countries with relaxed prescription drug laws where topical anesthetics are available over-the-counter; however several cases of anesthetic keratopathy have recently been reported in countries with stricter dispensing laws. Improper or uninformed prescribing by optometrists, ophthalmologists, and even otolaryngologists appears to be part of the problem. ${ }^{2}$
This is illustrated well in a case presented by Lee and Stark, which describes the development of anesthetic keratopathy in a patient after photorefractive keratectomy. The patient was given diluted tetracaine $(0.05 \%)$ in a bottle labeled "comfort drops" and had been using the drops frequently throughout the day. ${ }^{12}$ The patient was given no direction on the dose and frequency of the anesthetic, nor was she warned about the risk of overuse. It is imperative that patients understand the risks of improper use of anesthetic drops. Rao et al described a case of anesthetic keratopathy in a 42-year-old female who used three bottles of topical oxybuprocaine in one week to control severe postoperative pain after laser-assisted subepithelial keratectomy. The patient had been instructed to use the drops minimally, and only in cases of intolerable pain; but she was not warned of the risks associated with overuse. ${ }^{13}$ Both of these cases clearly demonstrate the need for increased physician awareness and better patient education on the risks associated with topical anesthetic overuse.

\section{Conclusion}

Our case of anesthetic keratopathy presenting as bilateral Mooren's ulcers represents a rare but important consequence of topical anesthetic abuse. We suggest that anesthetic abuse should be in the differential for any patient presenting with symptoms of acute vision loss, ring-shaped stromal infiltrates, and non-healing epithelial defects.

\section{Disclosure}

The authors report no conflicts of interest in this work.

\section{References}

1. Yagci A, Bozkurt B, Egrilmez S, et al. Topical anesthetic abuse keratopathy: a commonly overlooked health care problem. Cornea. 2011; 30(5):571-575.

2. Penna EP, Tabbara KF. Oxybuprocaine keratopathy: a preventable disease. Br J Ophthalmol. 1986;70(3):202-204.

3. Katsimpris JM, Sarantoulakou M, Kordelou A, Petkou D, Petropoulos IK. Clinical findings in patients with topical anaesthetic abuse keratitis: a report of five cases. Klin Monbl Augenheilkd. 2007;224(4):303-308. German.

4. Ardjomand N, Faschinger C, Haller-Schober EM, Scarpatetti M, Faulborn J. A clinico-pathological case report of necrotizing ulcerating keratopathy due to topical anaesthetic abuse. Ophthalmologe. 2002; 99(11):872-875. German

5. Klima M, Ruckerova H. Severe eye damage due to oxybuprocaine. Cesk Oftalmol. 1974;30:375-380. Czech.

6. Kintner JC, Grossniklaus HE, Lass JH, et al. Infectious crystalline keratopathy associated with topical anesthetic abuse. Cornea. 1990;9(1): $77-80$.

7. Risco JM, Millar LC. Ultrastructural alterations in the endothelium in a patient with topical anesthetic abuse keratopathy. Ophthalmology. 1992 99(4):628-633.

8. Chen HT, Chen KH, Hsu WM. Toxic keratopathy associated with abuse of low dose anesthetic. A case report. Cornea. 2004;23(5):527-529. 
9. Varga JH, Rubinfeld RS, Wolf TC, et al. Topical anesthetic abuse ring keratitis: report of four cases. Cornea. 1997;16(4):424-429.

10. Rosenwasser GO, Holland S, Pflugfelder SC, et al. Topical anesthetic abuse. Ophthalmology. 1990;97(8):967-972.

11. Wilson FM. Toxic and allergic reactions to topical ophthalmic medications. In: Arffa RC, editor. Grayson's Diseases of the Cornea. 3rd ed. St Louis, MO: Mosby Year Book; 1991.
12. Lee JK, Stark WJ. Anesthetic keratopathy after photorefractive keratectomy. J Cataract Refract Surg. 2008;34(10):1803-1805.

13. Rao SK, Wong VWY, Cheng ACK, Lam PTH, Lam DSC. Topical anesthetic-induced keratopathy after laser-assisted subepithelial keratectomy. J Cataract Refract Surg. 2007;33(8):1482-1484.

\section{Publish your work in this journal}

Clinical Ophthalmology is an international, peer-reviewed journal covering all subspecialties within ophthalmology. Key topics include: Optometry; Visual science; Pharmacology and drug therapy in eye diseases; Basic Sciences; Primary and Secondary eye care; Patient Safety and Quality of Care Improvements. This journal is indexed on

\section{Dovepress}

PubMed Central and CAS, and is the official journal of The Society of Clinical Ophthalmology (SCO). The manuscript management system is completely online and includes a very quick and fair peer-review system, which is all easy to use. Visit http://www.dovepress.com/ testimonials.php to read real quotes from published authors. 